\title{
Computer simulation of sputtering of graphite target in magnetron sputtering device with two zones of erosion
}

\author{
R.V. Bogdanov*, O.M. KOSTIUKEVYCH \\ Taras Shevenko National University of Kyiv, Faculty of Radio Physics, Electronics and Computer Systems, 4G, \\ Prospekt Hlushkov, Kyiv, Ukraine
}

\begin{abstract}
A computer simulation program for discharge in a magnetron sputtering device with two erosion zones was developed. Basic laws of the graphite target sputtering process and transport of sputtered material to the substrate were taken into account in the Monte Carlo code. The results of computer simulation for radial distributions of density and energy flux of carbon atoms on the substrate (at different values of discharge current and pressure of the working gas) confirmed the possibility of obtaining qualitative homogeneous films using this magnetron sputtering device. Also the discharge modes were determined for this magnetron sputtering device, in which it was possible to obtain such energy and density of carbon atoms fluxes, which were suitable for deposition of carbon films containing carbon nanotubes and other nanoparticles.
\end{abstract}

Keywords: Monte Carlo computer simulation; magnetron sputtering; flux of particles; carbon; graphite target; energy of particles

(C) Wroclaw University of Technology.

\section{Introduction}

In previous studies the authors developed a computer simulation program of electrical discharge in a flat (disc-shaped) magnetron sputtering device (hereinafter called MSD) with two zones of erosion [1-3]. The code was based on the Monte Carlo method for description of collisions of particles (electrons and ions) with the working gas atoms. The program was written in $\mathrm{C \#}$ programming language. The influence of the width of the cathode sheath on the current distribution on the cathode-target surface was evaluated [1]. The double-layer targets (copper on steel) were used to determine the geometrical dimensions of the erosion regions at different discharge currents in our experiments [2]. In order to check the effect of the current density (at the cathode-target) on the thickness of the cathode sheath, based on the Child-Langmuir law, a target divided into concentric zones for direct measurements of current was used [3]. The computer model showed the discharge behavior, which was consistent with real experimental results.

\footnotetext{
*E-mail: RSemsterFX@gmail.com
}

It is well known that the process of the magnetron sputter deposition of thin films can be divided into three main phases [4]: sputtering of the target material, transport of the sputtered material from the target area to the substrate, deposition of material on the substrate.

Sputtering of the target material in a MSD is closely connected with the discharge parameters in it. The efficiency of ionization in the MSD is increased significantly in comparison to the diode discharge system without a magnetic field, which provides the pressure reduction of the working gas and, consequently, better conditions of material transport from the target to the substrate, which is distanced from the region of sputtering. As a result, higher purity of obtained films is achieved and electron bombardment of substrate is reduced [5].

The average energy of atoms, sputtered from the target by ions, reaches up to tens $\mathrm{eV}$, which is much more than their energy of thermal evaporation [6]. This energy depends on material, which has been sputtered and on the energy of ions from the discharge plasma, which bombard the cathodetarget. Collisions with the working gas atoms result in decreasing of the energy of sputtered particles, which may also be used for such 
processes of nanotechnology, like cluster formation [7].

A case of the application of magnetron deposition of carbon films, which contained carbon nanotubes and other nanoparticles, was described in $[8,9]$. In these articles, the reactor graphite target with an area of $100 \mathrm{~cm}^{2}$, containing plates of catalytic metals was mentioned. The range of argon working gas pressures was $\mathrm{p}=2.66$ to $4.32 \mathrm{~Pa}$. The discharge currents were $\mathrm{I}_{d}=40$ to $100 \mathrm{~mA}$ at the voltages $\mathrm{U}_{d}=400$ to $600 \mathrm{~V}$. The magnetic field over the target was $\mathrm{B}=0.02 \mathrm{~T}$. The substrate was located at a distance of $4 \mathrm{~cm}$ from the cathodetarget [8] or at a distance of 3 to $5 \mathrm{~cm}$ [9]. The film deposition rate reached $6 \mathrm{~nm} / \mathrm{min}$ [8].

It was indicated in [10] that making 4 covalent bonds of carbon atoms needs excited electronic level with energy of $7.04 \mathrm{eV}$. In [11] it was mentioned that formation of the $\mathrm{sp}^{2}$ bounded carbon films requires impacting energy of carbon ions beam in a range of 10 to $40 \mathrm{eV}$. At higher energies (up to $1 \mathrm{keV}$ ) the $\mathrm{sp}^{3}$ bounded diamond-like films are observed. Obviously, the energy above $7.04 \mathrm{eV}$ is required for the formation of carbon films containing nanotubes.

The uneven discharge regions over the cathodetarget lead to its uneven sputtering. For searching the ways of increasing the usage of a target material and improving the quality of deposited coatings, the Monte Carlo computer simulations for various MSDs are widely used [12-15]. Similar Monte Carlo algorithm has been proposed in the current work.

The aim of the current work is the analysis of discharge conditions in the MSD with two zones of erosion and graphite target by computer simulation. The simulation is based on the parameters obtained from the real experiments: working gas pressure, voltage and current of the discharge in the MSD.

\section{Selected initial experimental data}

The MSD with two zones of erosion has a flat disc-shaped cathode (cathode unit) with a diameter of about $80 \mathrm{~mm}$, which contains a magnetic system [16] (Fig. 1a). The target is removable and placed on the cathode. Therefore, the cathode with the mounted target is called "cathode-target". In the calculations, the origin of cylindrical coordinates has been placed in the center of the target surface (Fig. 1a). In this series of experiments, the target was made of a graphite powder, which was compressed into a non-magnetic steel disc. This target has been used for further study of the conditions of carbon films synthesis.

The diameter of the target is $74 \mathrm{~mm}$ and its thickness reaches up to $1.5 \mathrm{~mm}$. To improve the efficiency of using the target material, two discharge zones have been formed in this MSD due to the special configuration of the magnetic field (Fig. 1b, 1c, 1d). Upon increasing the distance $h$ to the cathode surface, the magnetic field induction decreases by e times on $3.2 \mathrm{~mm}$ in the internal discharge zone and on $6.4 \mathrm{~mm}$ in the external one $[1,2]$. At this stage of our research we have neglected the influence of the target thickness on the magnitude of the magnetic field over the cathode-target.

The anode, made of an annular copper tube (socalled "extended anode" [17]) is placed above the cathode, and similar to the cathode it is cooled with oil, which flows through the cavity therein (Fig. 1a). The MSD and the above-placed substrate, on which the coating is deposited, are placed in a vacuum chamber of an industrial vacuum setup VUP-5.

Before the experiments, the vacuum chamber was evacuated to $p=5.32 \mathrm{mPa}$. After that the chamber was filled with argon (Ar) at five working pressures of $0.532 \mathrm{~Pa}, 1.33 \mathrm{~Pa}, 3.32 \mathrm{~Pa}, 6.65 \mathrm{~Pa}$, 13.3 Pa. The current-voltage (I-V) characteristics of the discharge were experimentally measured at the different pressures of argon. At the discharge current $\mathrm{I}_{d}=10$ to $15 \mathrm{~mA}$, only the ignition in one discharge zone was observed, but in this article such modes are not considered. At currents above $\mathrm{I}_{d}=20 \mathrm{~mA}$, the ignition in both zones of discharge was observed and its intensity ratio varied depending on the working gas pressure, the discharge voltage and current (Fig. 1c, 1d). At $\mathrm{p}=0.532 \mathrm{~Pa}$ the changes in the discharge current $\mathrm{I}_{d}=20$ to $130 \mathrm{~mA}$ were accompanied by the changes in the discharge voltage, $\mathrm{U}_{d}=374$ to $618 \mathrm{~V}$, and for 


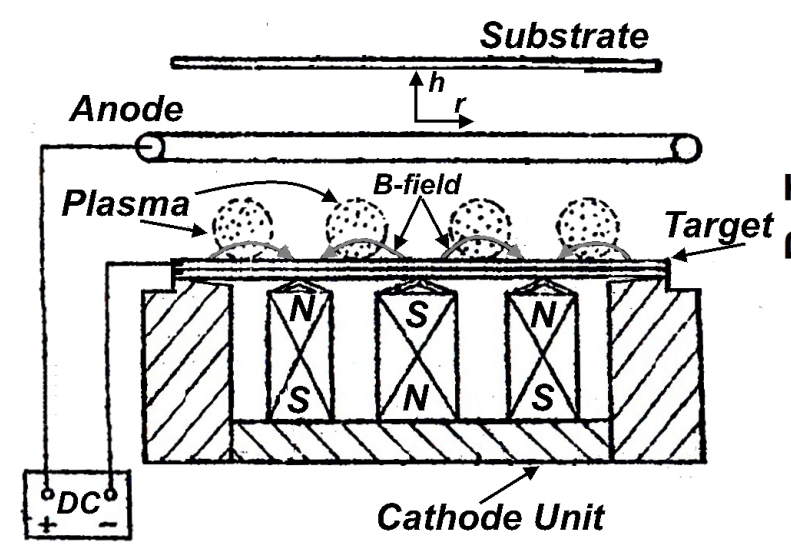

(a)

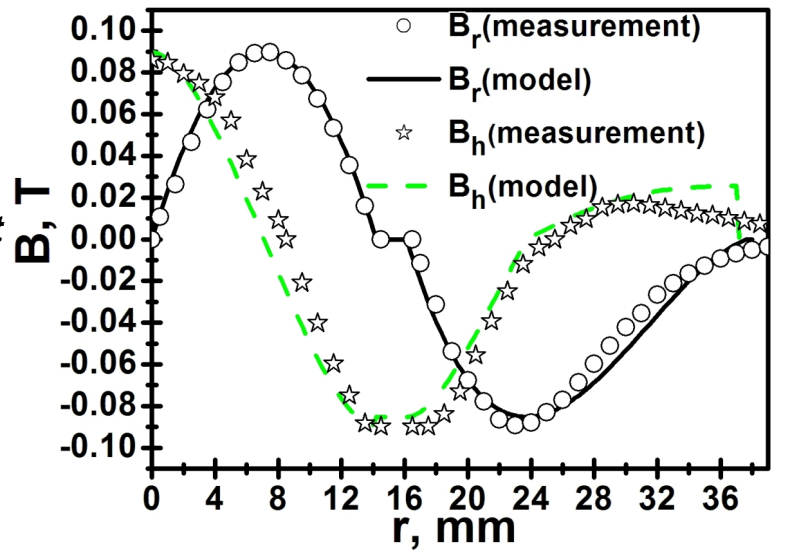

(b)

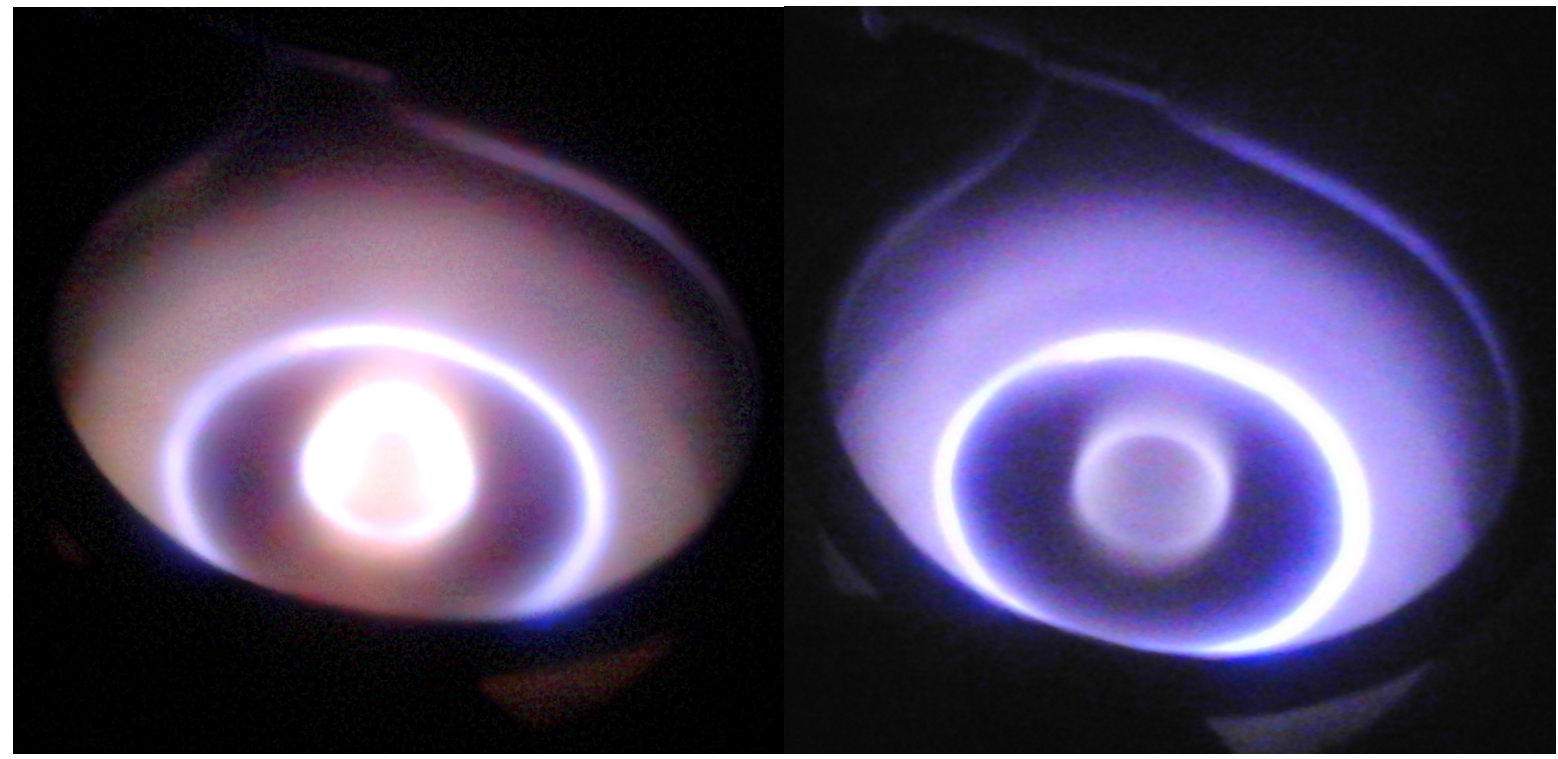

(c)

(d)

Fig. 1. MSD with two zones of erosion (a) scheme of MSD, (b) experimental and computational components of magnetic field induction on the target surface $\left(\mathrm{B}_{r}-\right.$ radial, $\mathrm{B}_{h}-$ vertical), (c) a photo of the discharge mode with intensive inner zone $\left(\mathrm{p}_{A r}=0.532 \mathrm{~Pa}, \mathrm{I}_{d}=130 \mathrm{~mA}\right.$, (d) a photo of the discharge mode with intensive outer zone $\left(\mathrm{p}_{A r}=6.65 \mathrm{~Pa}, \mathrm{I}_{d}=100 \mathrm{~mA}\right)$.

$\mathrm{p}=13.3 \mathrm{~Pa}$ the respective voltage changes ranged from $\mathrm{U}_{d}=286$ to $396 \mathrm{~V}$.

\section{Computer model of the MSD and the results for the ion current density}

The computer model is based on the geometrical dimensions of MSD with two erosion zones, which were derived from the experimental values of magnetic field and the parameters considered earlier in [1-3] (Fig. 1b). The electric field was chosen as in an ordinary glow discharge with the main voltage drop in the cathode sheath region $[1,2]$ :

$$
E_{h}(r, h)=-\left(2 V_{d} / d_{E}(r)\right) \cdot\left(1-\left(h / d_{E}(r)\right)\right)
$$

where $\mathrm{V}_{d}$ - voltage drop on the cathode sheath (assumed as equal to the discharge voltage $\left.\mathrm{U}_{d}\right), \mathrm{d}_{E}(\mathrm{r})$ - the sheath width at the cathode-target radius $r$, 
$\mathrm{h}$ - the vertical coordinate in a cylindrical coordinate system with the starting point at the cathode. Outside the cathode sheath, $\mathrm{E}_{h}(\mathrm{r}, \mathrm{h})=-25 \mathrm{~V} / \mathrm{m}$ $[1,2]$. Initial values of the $\mathrm{d}_{E}(\mathrm{r})$ are proportional to $\left(\mathrm{B}_{r}(\mathrm{r})\right)^{-1}$, where $\mathrm{B}_{r}(\mathrm{r})$ is the value of the radial component of magnetic field induction on the cathode-target surface (Fig. 1b) [1]. The maximum width of the cathode sheath $-\mathrm{d}_{E}=3.7 \mathrm{~mm}$ - was chosen as unachievable in the discharge zones in a case when they both are ignited (at currents above $\mathrm{I}_{d}=15$ to $20 \mathrm{~mA}$ ), which resulted in increasing the computation speed [3].

In the computer model, the distance between the cathode-target and substrate was assumed as $40 \mathrm{~mm}$. The discharge was calculated for the distance between the cathode and anode equal to $35 \mathrm{~mm}$. The cathode-target and the substrate had the same radius of $38 \mathrm{~mm}$. For the modeling, we selected the operating currents in the range of $\mathrm{I}_{d}=20$ to $130 \mathrm{~mA}$ and appropriate discharge voltage $\mathrm{U}_{d}$ at five argon (Ar) working gas pressures, which have been presented above. The cathodetarget and the substrate were conventionally divided into the concentric "measuring rings", $1 \mathrm{~mm}$ wide (as in [3]). This "measuring rings" were used to determine the current and particles distributions along the radius. Then, the term ' $r$ ' denoted the average radius of each ring. The discharge was measured from the center of the cathode-target, where the starting point for the radius $r=0$.

At the first stage of the computer simulation we calculated the motion equations in crossed electric and magnetic fields for several thousands of secondary electrons released from the cathode surface. At the initial step in the computer modeling of cathode sheath, an approximation of $\mathrm{d}_{E}(\mathrm{r})$ was used (see the example in Fig. $2 \mathrm{~b}-\mathrm{d}_{E-\text { model }}$ ). During the movement in electric field the charged particles get energy, which is partially lost in collisions with atoms of the working gas (hereinafter called AWG). The probability of each type of collision was estimated at each time step of simulation and compared with generated random number (the Monte Carlo method). We considered the following types of electron collisions with AWG: elastic, excitation of atomic electron levels, ionization.
After escape of electrons from the discharge volume, the calculation of the movement of the emerging ions starts. The negative cathode potential, at which the ions accelerate and move almost along a straight line from the point of origin to the cathode determines this movement. This allows us to find so-called "self-consistent" positions of secondary electrons from the cathode. They are also based on the conditions of secondary ion-electron emission [3, 14]. At the ordinary step of searching for "self-consistent" positions, direct projections of the positions of ions appearing on the cathode surface are used. The relative distribution of these projections on the cathode surface is proportional to the ion current $\mathrm{I}_{i}$ distribution on it, which is almost equal to the discharge current $\mathrm{I}_{d}$.

The thickness of the cathode sheath $\mathrm{d}_{E}(\mathrm{r})$ is calculated from the distribution of ion current density on the cathode-target $\mathrm{j}_{i}$ (r) (Fig. 2a) by the ChildLangmuir law [5]. Here is the final formula, in which the dimension of $\mathrm{d}_{E}$ is $\mathrm{mm}[2,3]$ :

$$
d_{E}(r)=2.43 \cdot 10^{-3} \cdot\left(V_{d}^{0.75} /\left(M_{i}^{0.25} \cdot\left(j_{i}(r)\right)^{0.5}\right)\right)
$$

where $\mathrm{j}_{i}(\mathrm{r})$ - the ion current density on the "measuring ring" with the radius $\mathrm{r} ; \mathrm{M}_{i}$ - atomic mass of the working gas ions (for $\operatorname{argon} \mathrm{M}_{i}=40$ a.m.u.).

At the current version of the code, to increase the calculation speed, at each step of ions generation, a new configuration of the cathode sheath $\mathrm{d}_{E-\text { model }}(\mathrm{r})$, defined by the same approximation as at the initial step but with new minimal values of $\mathrm{d}_{E}(\mathrm{r})$ from (2) in the effective ionization zones is used (Fig. 2b). In the two zones, the average current density is assumed as higher (or equal) than $50 \%$ of the maximum value of current density in each area. In Fig. 2b we can see a comparison of the model approximation of the cathode sheath $\mathrm{d}_{E-\text { model }}(\mathrm{r})$ - and the final reconstruction of it from (2) $-d_{E-\text { result }}(r)$ based on the density radial distribution of the ion current $j_{i}(r)$. Fig. $2 b$ demonstrates sufficient accuracy of the model in the areas, which we are interested in.

In the newly discovered zones of intense ionization for the new configuration of the cathode sheath $d_{E}(r)$, the initial number of electrons starts 
at the cathode-target surface. In the following step, a comparison of previous and current number of ions, which have been generated by one electron, is carried out. If the difference is less than $10 \%$, then the self-consistent conditions in the cathode sheath are considered as achieved. Then, the movement of ions is calculated from the motion equations. Their number and energy distributions on the cathode-target surface are also evaluated. On this basis we can determine the density of the flow and the energy of the sputtered particles (this will be discussed in Part 4 of the article).

The simulation results for the distributions of ion current densities on the cathode-target for the discharge current $\mathrm{I}_{d}=100 \mathrm{~mA}$, are shown in Fig. 2a.

We can see that at the discharge current $\mathrm{I}_{d}=100 \mathrm{~mA}$ and at different pressures, the ratio of current densities between the inner and outer discharge zones changes (Fig. 2a). At pressures up to $\mathrm{p}=1.33 \mathrm{~Pa}$ (and to some extent at $\mathrm{p}=13.3 \mathrm{~Pa}$ ) the ion current density $\mathrm{j}_{i}(\mathrm{r})$ in the inner discharge zone exceeds the ion current density in the outer zone. Ion current density in the outer zone does not change so much with changes in the working gas pressure. It can be seen in the actual experimental results for this target (Fig. 1c, 1d).

The dependencies for the minimum thickness of the cathode sheath $\mathrm{d}_{E-\min }$, which have been averaged over the both discharge zones for different pressures, are shown in Fig. 3a. The dependencies for the mean energy $\left\langle\mathrm{W}_{i}\right\rangle$ of particles (plasma ions, atoms), which bombard the cathode-target, are shown in Fig. $3 b$.

It can be seen that in these simulation results, the cathode sheath at discharge currents $\mathrm{I}_{d}=70$ to $130 \mathrm{~mA}$ has a thickness of about $\mathrm{d}_{E}=1 \mathrm{~mm}$ (Fig. 3a). When the discharge current and the ion current densities decrease the cathode sheath becomes wider (Fig. $2 b$ and Fig. 3a). Perhaps for $\mathrm{p}=0.532 \mathrm{~Pa}$, and often for $\mathrm{p}=1.33 \mathrm{~Pa}$, the most advantageous conditions are realized for the magnetic confinement of the electrons near the cathode (Fig. 3a). However, at the pressures greater than $\mathrm{p}=3.32 \mathrm{~Pa}$ the $\mathrm{d}_{E-\min }$ is reduced, with a significant reduction of $\mathrm{U}_{d}$ at the same discharge currents. The $\mathrm{U}_{d}$ reduction with increasing pressure also reduces the ions energy $\left\langle\mathrm{W}_{i}\right\rangle$ (Fig. 3b) at the same discharge current $\mathrm{I}_{d}$.

\section{Computer modeling of carbon target sputtering and atoms trans- port}

From the distribution of ion current density $\mathrm{j}_{i}(\mathrm{r})$ on the surface of the cathode-target and the energy of ions that bombard the cathode we can estimate the transport characteristics of carbon atoms sputtered from the target onto the substrate. It was made using the computer model of the sputtering process and the transport of atoms of sputtered material based on the Monte Carlo method. The physical model takes into account the following provisions:

1. The yield of sputtered material is estimated by the theory of Sigmund (for the ion energies less than $1 \mathrm{keV}$ ) [6]:

$Y\left(W_{i}\right)=\left(N_{2} / N_{1}\right)=$

$=\left(3 / 4 \pi^{2}\right) \cdot \alpha \cdot\left(4 M_{1} M_{2} /\left(M_{1}+M_{2}\right)^{2}\right) \cdot\left(W_{i} / U_{s}\right)$

where $\mathrm{W}_{i}$ - energy of incident ion; $\mathrm{M}_{1}$ and $\mathrm{M}_{2}$ - the mass of the incident ion and the target atom, respectively (in atomic mass units - a.m.u.); $\mathrm{N}_{2}$ and $\mathrm{N}_{1}-$ number of atoms sputtered from the target and the number of bombarding particles (atoms, ions), respectively; $\mathrm{U}_{s}$ - the binding energy between an atom and surface (for carbon taken $\left.\mathrm{U}_{s}=7.41 \mathrm{eV}[4,10]\right) ; \alpha-$ a dimensionless parameter, which depends on the ratio $M_{2} / M_{1}$, and the energy $E$. When $\left(\mathrm{M}_{2} / \mathrm{M}_{1}\right)<1$, the parameter $\alpha \approx$ 0.2. Thus, from the expression (3), for argon ions $\left(\mathrm{M}_{1}=40\right.$ a.m.u. $)$ with mean energies of $500 \mathrm{eV}\left(\mathrm{M}_{2}=12\right.$ a.m.u. $)$, in case of $\mathrm{U}_{s}=7.41 \mathrm{eV}$, the yield of carbon atoms $\mathrm{Y}=0.73$. Therefore, the flow of sputtered particles is determined by the flow of ions and sputtering coefficient $\mathrm{Y}$ from formula (3);

2. The velocity vector of the sputtered atoms has a certain angle relative to the normal 


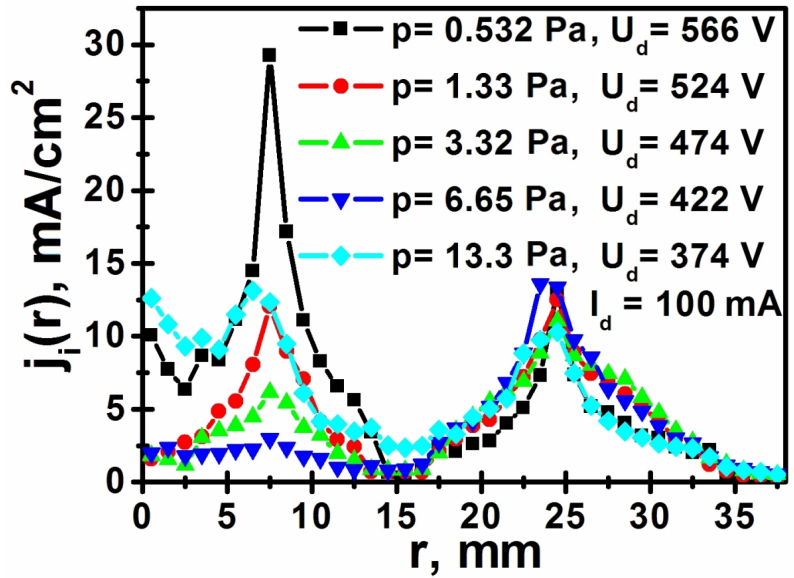

(a)

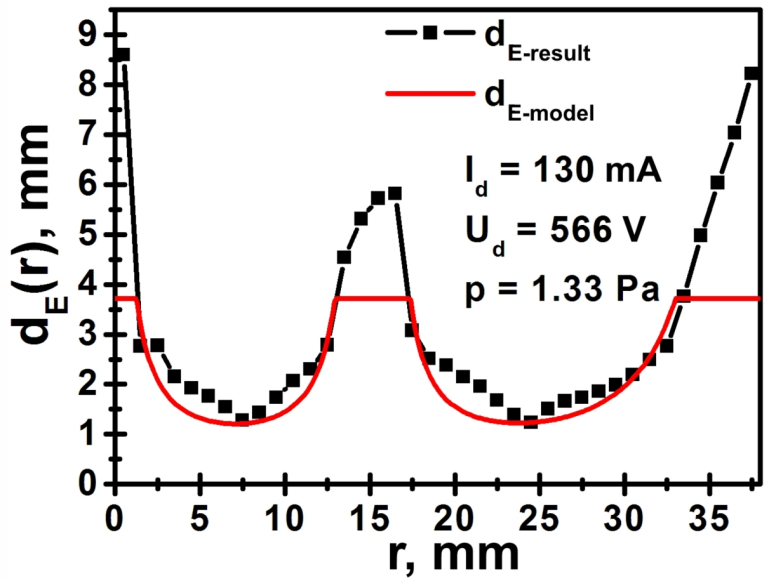

(b)

Fig. 2. Radial distributions of (a) ion current density on the target surface, (b) cathode sheath thickness calculated from the model $-\mathrm{d}_{E-\text { model }}$ and the simulation result $-\mathrm{d}_{E-\text { result }}$.

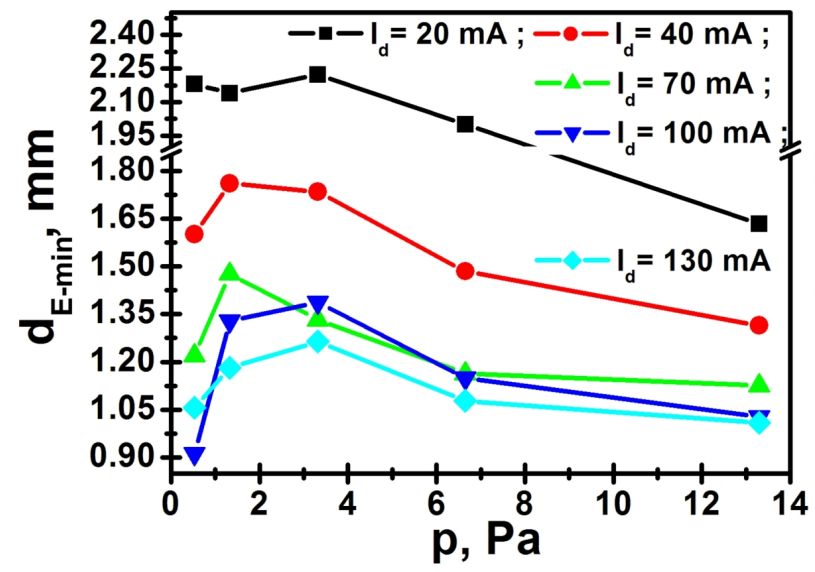

(a)

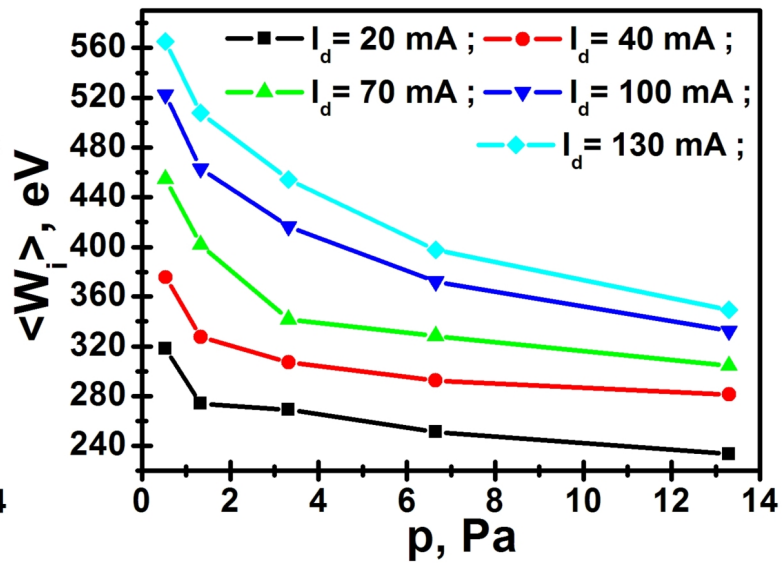

(b)

Fig. 3. (a) Minimum thickness of cathode sheath averaged over the both discharge zones and (b) energy of ions incident on the cathode-target versus pressure at different current values.

to the target surface [4, 7]. This angular distribution of sputtered atoms is usually described by the "cosine law":

$$
j(\theta)=j(0) \cdot \cos (\theta)
$$

where $\theta$ - the angle relative to the normal to the target surface (in the simulation it was defined by a random number); $j(0)$ - the current density given at a point of target.

The energy of sputtered particles can be defined by Thomson distribution [6], but at this stage of the research an average energy of sputtered particles obtained from this distribution was used (equation 8);

3. Motion of atomic particles through the working gas is determined by the mean free path, calculated on the basis of the "model of quasi-hard spheres" (equation 9) [18]. The probability of collision was determined at each time step (for carbon the time step is $\Delta \mathrm{t} \approx 10^{-9} \mathrm{~s}$ ) on the basis of the mean free path in these conditions, and compared with a random number:

$$
r n d<(1-\exp (-\Delta s / \lambda))
$$


where rnd - a random number (from 0 to 1), generated at each time step - length traversed by a particle per time step, $\lambda$ - the mean free path of a particle under these conditions. A similar criterion was used in the previous simulation of the discharge [1$3,13]$.

So-called threshold energy of sputtering $\mathrm{W}_{t h}$ in the case $\left(\mathrm{M}_{2} / \mathrm{M}_{1}\right) \leqslant 1$ is (according to [6]):

$$
W_{t h}=6.7 \cdot U_{s} / a
$$

where a - the coefficient of energy transfer from the atom number 1 to the atom number 2 :

$$
a=4 M_{1} M_{2} /\left(M_{1}+M_{2}\right)^{2}
$$

Accordingly, $\mathrm{a} \approx 0.71$ for carbon and argon atoms, and the threshold energy: $\mathrm{W}_{t h} \approx 9.44 \cdot \mathrm{U}_{s}=$ $69.95 \mathrm{eV}\left(\right.$ at $\left.\mathrm{U}_{s}=7.41 \mathrm{eV}\right)$.

In [6] it was presented the estimation of the average energy of the sputtered atoms, taking into account the energy $\mathrm{W}_{t h}$ from equation 6:

$$
\left\langle W_{s a}\right\rangle=2 U_{s}\left(\ln \left(W_{i} / W_{t h}\right)-1.5\right)
$$

Respectively, for ions with an average energy $\mathrm{W}_{i}=500 \mathrm{eV}$ of the sputtered atoms, $\left\langle\mathrm{W}_{s a}\right\rangle=6.918 \mathrm{eV}$ and for $\mathrm{W}_{i}=313.494 \mathrm{eV}$, the average energy $\left\langle\mathrm{W}_{s a}\right\rangle=0$. Obviously, for sputtering based on this criterion the best suited are the modes at discharge currents higher than $\mathrm{I}_{d}=70 \mathrm{~mA}$, in which the discharge voltage provides sufficient acceleration of the ions of the working gas (Fig. 3b).

In the quasi-hard spheres interaction model for collision cross section calculation the minimum radius to approach the center of an atom, (in $\AA$ ) is [18]:

$$
\begin{aligned}
& r_{\min }\left(W_{c}\right)=-0.122 \cdot\left(Z_{1}^{0.0387}+Z_{2}^{0.0387}\right) \cdot \\
& \cdot \ln \left(\left(W_{c} / 95.863\right) \cdot\left(Z_{1} Z_{2}\right)^{-0.7383}\right)
\end{aligned}
$$

where $Z_{1}$ and $Z_{2}$ are the atomic numbers of the incident atom and the target atom, respectively; $\mathrm{W}_{c}-$ the energy of relative motion of the system center of mass in $e V$. For carbon $\mathrm{Z}_{1}=6$, and for argon $\mathrm{Z}_{2}=18$.
Assuming that the energy of atoms of a background gas is much less than the energy of the incident particles $\left\langle\mathrm{W}_{s a}\right\rangle$, then $\mathrm{W}_{c}$ - the energy of relative motion of the center of mass will be (in $\mathrm{eV}$ ):

$W_{c} \approx\left(M_{c} /\left(M_{c}+M_{A r}\right)\right)^{2}\left\langle W_{s a}\right\rangle \approx 5.325 \times 10^{-2}\left\langle W_{s a}\right\rangle$

where $\mathrm{M}_{c}$ and $\mathrm{M}_{A r}$ - mass of carbon and argon atoms, respectively.

After substituting the corresponding values for argon and carbon in equation 8 , we obtain $\left\langle\mathrm{W}_{s a}\right\rangle=6.929 \mathrm{eV}$, and then, from equations 9 and 10: $\mathrm{r}_{\min }\left(\mathrm{W}_{c}\right)=2.41 \AA$. Now we can estimate the mean free path $\lambda$ of carbon atoms in argon at $\mathrm{T}=293.16 \mathrm{~K}$ :

$$
\begin{gathered}
\lambda(W)=\left(n_{A r} \cdot \pi \cdot r^{2}(W)\right)^{-1} \\
\lambda(6.929 \mathrm{eV})=p^{-1} \cdot 22.18 \mathrm{~mm}
\end{gathered}
$$

where $\mathrm{p}$ - pressure in $\mathrm{Pa}$.

Thus, at a pressure $\mathrm{p}=0.532 \mathrm{~Pa}$, the mean free path of carbon in argon is $\lambda=41.69 \mathrm{~mm}$, which is comparable to the typical distance between the target and the substrate in $[9,10]$, and when $p=6.65 \mathrm{~Pa}$ the value of $\lambda$ is $3.335 \mathrm{~mm}$.

The limit number of central elastic collisions, after which the energy of the sputtered atoms becomes equal to the energy of AWG, was estimated in [4] as:

$$
N_{t h}=\lg \left(\left\langle W_{g}\right\rangle /\left\langle W_{s a}\right\rangle\right) / \lg \left(1-\left(W_{\max } /\left\langle W_{s a}\right\rangle\right)\right)
$$

where $\mathrm{W}_{\max }$ - the maximum energy that can be transmitted by a sputtered atom to AWG, (from equation 7 the $\left.\mathrm{W}_{\max }=\mathrm{a}\left\langle\mathrm{W}_{s a}\right\rangle\right),\left\langle\mathrm{W}_{g}\right\rangle$ - the average energy of the atoms of the working gas, at $\mathrm{T}=293.16 \mathrm{~K},\left\langle\mathrm{~W}_{g}\right\rangle=0.0379 \mathrm{eV}$, which provides the number of collisions $-\mathrm{N}_{t h} \approx 4.2$ (as at the values given previously $\left\langle\mathrm{W}_{s a}\right\rangle=6.918 \mathrm{eV}$ and $\mathrm{a} \approx$ 0.71 ). When $\left\langle\mathrm{W}_{s a}\right\rangle=10 \mathrm{eV}$ this value is $\mathrm{N}_{t h} \approx 4.5$, and for $\left\langle\mathrm{W}_{s a}\right\rangle=3 \mathrm{eV}: \mathrm{N}_{t h} \approx 3.5$. In case of offcenter collision of a carbon atom with the working gas, a smaller portion of energy is transmitted, whereby the carbon atoms are more likely to reach the substrate. In our computer model the probability of such collisions has been considered. 
Taking into account the ratio of secondary ionelectron emission, $\gamma_{e} \approx 0.1$, the ion current $\mathrm{I}_{i}$ to the cathode-target, which is divided into the "measuring rings" with the mean radius $r$, can be defined as:

$$
I_{i}=\sum_{r} I_{i}(r)=I_{d} /\left(1+\gamma_{e}\right) \approx I_{d} / 1.1
$$

where $\mathrm{I}_{d}$ - discharge current, $\mathrm{I}_{i}(\mathrm{r})$ - current of accelerated ions from the discharge on each ring. The unit of the currents is $\mathrm{mA}$.

From equation 13 we can determine the number of ions which pass per unit area in one second (in $\left.\mathrm{s}^{-1}\right)$ :

$$
G_{i}=I_{i} / e=N_{i} / t
$$

and the ions flux on the "measuring ring" area per one second (in $\mathrm{cm}^{-2} \cdot \mathrm{s}^{-1}$ ):

$$
\begin{gathered}
\Gamma_{i}(r)=G_{i}(r) / \Delta S \\
\Gamma_{i}(r)=j_{i}(r) / e
\end{gathered}
$$

where $\mathrm{I}_{i},-$ the ion current, $\mathrm{j}_{i}(\mathrm{r})$ - ion current density at the "measuring ring" (in $\mathrm{mA} / \mathrm{cm}^{2}$ ), $\mathrm{N}_{i}-$ number of ions, $\Gamma_{i}-$ ion flux, $\Delta \mathrm{S}-$ the area of the "measuring ring", $\mathrm{G}_{i}(\mathrm{r})$ - the number of ions impinging on the "measuring ring", $\mathrm{t}-$ the time, $\mathrm{e}=1.6 \times 10^{-19} \mathrm{C}-$ the elementary charge.

From equations 3,14 and $15 \mathrm{~b}$ we can define the number of neutral particles that are sputtered from the cathode-target surface at one "measuring ring" (in $\mathrm{s}^{-1}$ ):

$$
G_{c}(r)=Y\left(W_{i}\right) \cdot I_{i}(r) / e
$$

and the flux density on the surface of one target ring, $\Gamma_{c}\left(\right.$ in $\left.\mathrm{cm}^{-2} \cdot \mathrm{s}^{-1}\right)$ :

$$
\Gamma_{c}(r)=Y\left(W_{i}\right) \cdot j_{i}(r) / e
$$

where $\mathrm{Y}\left(\mathrm{W}_{i}\right)$ - the sputtering yield from equation 3 related to the energy of the incident ions $\mathrm{W}_{i}(\mathrm{r}) ; \mathrm{I}_{i}(\mathrm{r})$ and $\mathrm{j}_{i}(\mathrm{r})$ - the ion current and the ion current density, which were defined above.
The relation between the actual number of particles which come to the substrate with the number in computer simulation can be expressed as:

$$
G_{t}=\left(N_{t}^{*} / N_{c}^{*}\right) G_{c}
$$

where $\mathrm{N}_{c}^{*}$ - the number of particles emerging from the cathode-target in the computer simulation, $\mathrm{N}_{t}^{*}-$ the number of particles reaching the substrate in the computer simulation, $\mathrm{G}_{c}$ - actual number of particles, which emerge from the target equation 16. In similar way the distribution of the particles flux density on the substrate $\Gamma_{t}(\mathrm{r})$ was defined in the computer model.

The energy distribution $\mathrm{W}_{t}(\mathrm{r})$ for atoms that reached the substrate is one of the simulation results.

\section{Results of computer simulation for the flow of sputtered carbon atoms}

The discharge currents $\mathrm{I}_{d}=70 \mathrm{~mA}, 100 \mathrm{~mA}$, $130 \mathrm{~mA}$ were selected, because at these currents and at considered pressures ( 0.532 to $13.3 \mathrm{~Pa})$ the effective sputtering might be obtained (as we could see before).

Distributions of the particle flux along the radius for two extreme cases of the operating pressure of $\operatorname{Ar}(\mathrm{p}=0.532 \mathrm{~Pa}, \mathrm{p}=13.3 \mathrm{~Pa})$ are shown in Fig. 4. As we can see, the flux density distribution of the sputtered particles for $\Gamma_{c}(r)$ is virtually identical to the density distribution of the ion flux $\Gamma_{i}(\mathrm{r})$ on the surface of the target, but smaller in magnitude by $\left(\mathrm{Y}\left(\mathrm{W}_{i}\right)\right)^{-1}$ times. The flux density on the substrate $\Gamma_{t}(\mathrm{r})$ is noticeably less than $\Gamma_{c}(\mathrm{r})$, but in contrast, it has greater uniformity along the radius in comparison with the initial distribution of the $\Gamma_{c}(\mathrm{r})$, which has two clearly defined maxima.

Dependencies of the ratio of the ions and the sputtered particles numbers at various pressures and currents are shown in Fig. 5a. Dependencies of the average energy of the sputtered atoms $\mathrm{W}_{c}$, which have approached the substrate $\mathrm{W}_{t}$, are depicted in Fig. 5b. We can notice that the number of carbon atoms, which have been sputtered from the 


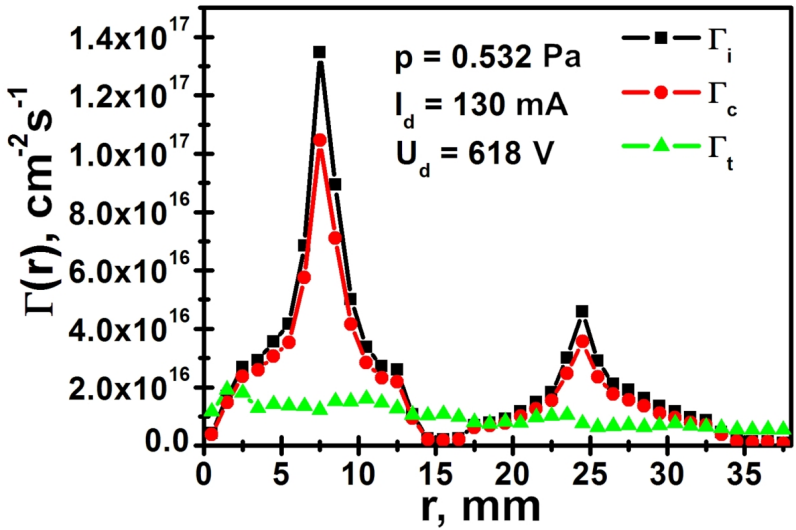

(a)

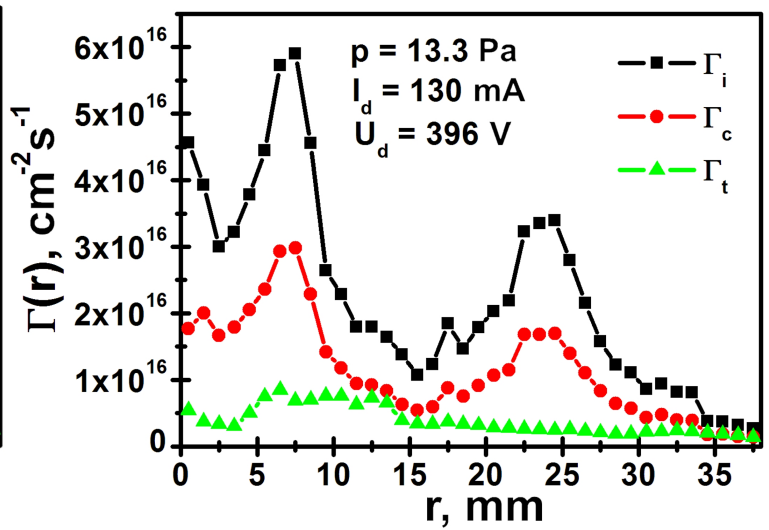

(b)

Fig. 4. Comparison of the results of simulation of the flux of particles density at different working pressures at a discharge current $\mathrm{I}_{d}=130 \mathrm{~mA}$, (a) at $\mathrm{p}=0.532 \mathrm{~Pa}$, (b) at $\mathrm{p}=13.3 \mathrm{~Pa}$.

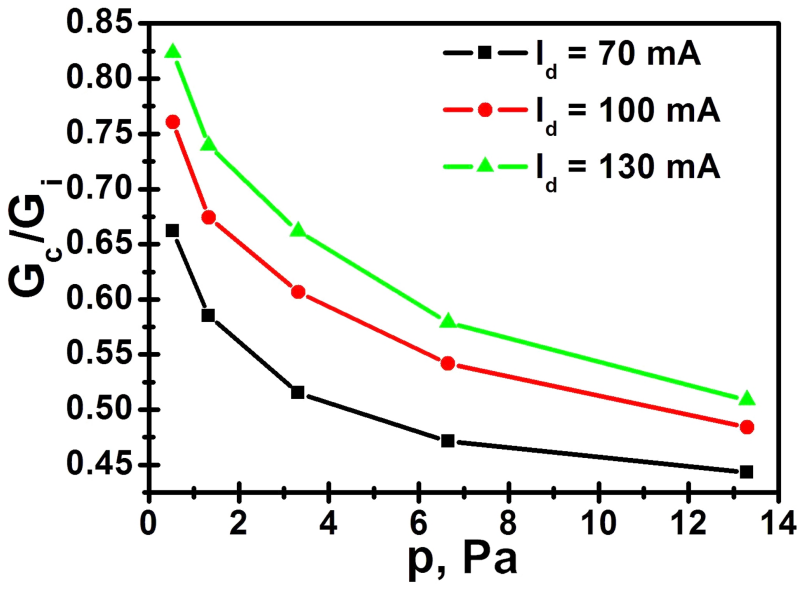

(a)

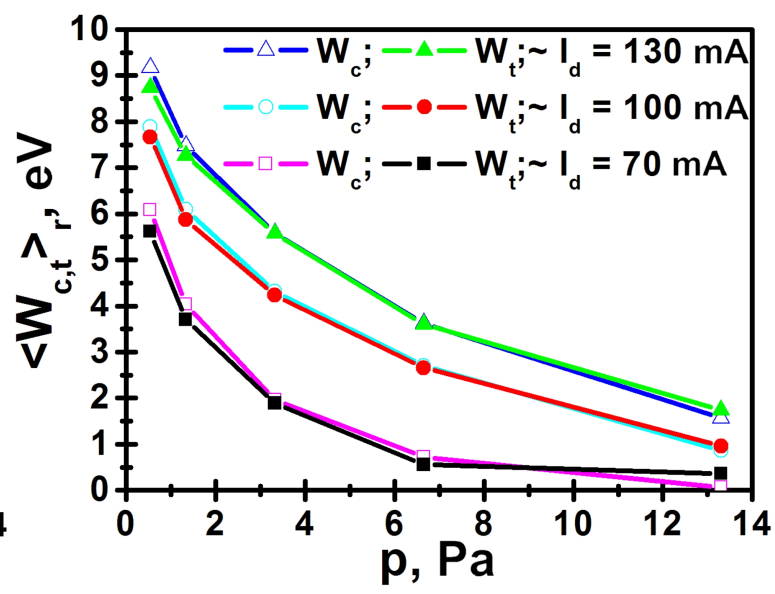

(b)

Fig. 5. (a) Ratio of the flux of sputtered atoms to the flow of ions bombarding the target, (b) the average energy of the sputtered atoms $\left\langle\mathrm{W}_{c}\right\rangle$ and the average energy of atoms approaching the substrate $\left\langle\mathrm{W}_{t}\right\rangle$ at different currents and pressures.

target surface is smaller when the discharge current becomes smaller and the working pressure becomes higher.

The carbon atoms energy (Fig. 5b) is directly related to the energy of ions bombarding the target (Fig. 3b). The average energy of atoms, which have reached the substrate, $\left\langle\mathrm{W}_{t}\right\rangle$ (Fig. 5b) does not differ very much from the energy of atoms emerging from the target $\left\langle\mathrm{W}_{c}\right\rangle$. Obviously, this is due to a small number of collisions at the pressure below $\mathrm{p}=6.65 \mathrm{~Pa}$, or the fact that the atoms, which have undergone a substantial number of collisions, could not reach the substrate (see below). Also we must notice that $\left\langle\mathrm{W}_{t}\right\rangle$ reaches and even exceeds the value of $7.04 \mathrm{eV}$ attainable, as mentioned above, only at pressures of $0.532 \mathrm{~Pa}$ and $1.33 \mathrm{~Pa}$ and the discharge currents of $100 \mathrm{~mA}$ and $130 \mathrm{~mA}$ (Fig. 5b).

Fig. 6 shows the plots of the number of collisions per atom released from the target $\mathrm{N}_{\text {coll }} / \mathrm{N}_{\mathrm{c}}$ at different pressures (Fig. 6a) (where $\mathrm{N}_{\text {coll }}$ - the number of collisions committed by all sputtered atoms, which total number is $-\mathrm{N}_{\mathrm{c}}$ ), and the ratio 
of the number of sputtered atoms that have undergone a collision $\mathrm{N}_{\text {acoll }}$ to the total number of atoms $\mathrm{N}_{\mathrm{c}}-\left(\mathrm{N}_{\mathrm{acoll}} / \mathrm{N}_{\mathrm{c}}\right)$ (Fig. 6b). With increasing pressure the $\mathrm{N}_{\text {coll }} / \mathrm{N}_{\mathrm{c}}$ also increases. The greatest number of collisions observed per atom is 4 at the pressure $\mathrm{p}=13.3 \mathrm{~Pa}$. This value is very close to the estimated value of the maximum number of collisions $\mathrm{N}_{\text {th }}$ from the expression 12.

It can be seen (Fig. 6b) that the relative number of atoms that collided with AWG at pressures less than $\mathrm{p}=6.65 \mathrm{~Pa}$ does not exceed $15 \%$ of the total, while for $\mathrm{p}=13.3 \mathrm{~Pa}$ this number reaches $45 \%$. Some differences at different currents can be explained by the changes in energy of sputtered atoms, which affect the collision cross-section, and through it, the mean free path (equation 9). The largest energy at discharge currents $\mathrm{I}_{d}=100 \mathrm{~mA}$ and $\mathrm{I}_{d}=130 \mathrm{~mA}$ corresponds to smaller crosssections of collisions, which is especially noticeable at the pressure $\mathrm{p}=13.3 \mathrm{~Pa}$ (Fig. 6b).

With increasing pressure, the losses of carbon atoms increase due to scattering on atoms of the working gas (Fig. 7a). At the working gas pressure $\mathrm{p}=0.532 \mathrm{~Pa}$, about $60 \%$ of sputtered atoms reach the substrate, and when $\mathrm{p}=13.3 \mathrm{~Pa}$ it is only 30 to $40 \%$. Comparing the number of atoms, which have reached the substrate and the number of ions that bombarded the cathode, we can see that the most intensive growth of losses takes place in the transition of argon working pressure from $p=0.532$ Pa to $p=1.33 \mathrm{~Pa}$ (Fig. 7b).

Fig. $6 \mathrm{~b}$ shows that with increasing pressure from $0.532 \mathrm{~Pa}$ to $13.3 \mathrm{~Pa}$ the number of atoms, which have collided increases on average by $34.0 \%$, and the loss of flow of atoms in Fig. $7 \mathrm{a}$ increases about $33.33 \%$ at all the considered currents.

To consider two extreme cases of the discharge current density distribution (at operating pressures $\mathrm{p}=0.532 \mathrm{~Pa}$ and $\mathrm{p}=6.65 \mathrm{~Pa}$ ), when the current density in one zone is much higher than in the other one (like in Fig. 1c, 1d), which must also have an influence on the distribution of sputtered material on the substrate (Fig. 8).

The highest density of atoms $\Gamma_{t}(\mathrm{r})$ on the substrate at $\mathrm{p}=0.532 \mathrm{~Pa}$ is observed near its center (Fig. 8b), which can be explained by greater density of sputtered particles in the inner zone of the discharge $\Gamma_{c}(\mathrm{r})$ (Fig. 8a). With increasing the distance from the center, the flux density is fairly evenly reduced, which may reduce the thickness of the deposited film in this region. At a pressure $\mathrm{p}=6.65 \mathrm{~Pa}$, the discharge configuration with the most intense outer zone is observed (Fig. 8b), which provides the highest density of sputtered particles $\Gamma_{c}(\mathrm{r})$ over the outer zone. Also the decreasing of flux density $\Gamma_{t}(\mathrm{r})$ to the center of MSD (Fig. 8d), and to the outer edge of the discharge is observed, as in the previous case (Fig. 8b).

Fig. $8 \mathrm{~b}$ and $8 \mathrm{~d}$ show that the region with the most homogeneous density of particles on the substrate surface is between two sputtering zones, because the density decreases when it approaches the edge of the target and, often, the center of discharge, which contributes to possible reduction of the film thickness at these locations.

Fig. 9 presents the distributions of the average energy of carbon atoms along the radius of the cathode-target and on the substrate. It can be noted that the radial distribution of the average energy on the surface of the substrate is more uniform than at the output of the target, which indicates the approximately equal energy conditions on the substrate surface along the radius. Similar behavior is observed at other pressures.

\section{Discussion}

From the results of the simulation we can see that the flux density of the carbon atoms on the substrate between the discharge zones is $\Gamma_{t}=2 \times 10^{15}$ to $9 \times 10^{15} \mathrm{~cm}^{-2} \cdot \mathrm{s}^{-1}$ (Fig. 7b, 7d). In [9] it, was disclosed that the growth rate of carbon film was $6 \mathrm{~nm} / \mathrm{min}$. In this case, the volume of the film fragment formed in a time of $1 \mathrm{~s}$ on an area of $1 \mathrm{~cm}^{2}$ is $10^{-8} \mathrm{~cm}^{3}$. Volumetric mass density of graphite is usually 1.8 to $2.35 \mathrm{~g} / \mathrm{cm}^{3}$ [19], which provides the mass of the film fragment $1.8 \times 10^{-8}$ to $2.35 \times 10^{-8} \mathrm{~g}$. Then, the atomic mass of carbon $\mathrm{M}_{c}=12 \mathrm{~g} / \mathrm{mol}$, and Avogadro number $\mathrm{N}_{A}=6.022169(40) \times 10^{23} \mathrm{~mol}^{-1}$, provide the flux density $\Gamma_{t}=0.9 \times 10^{15}$ to $1.18 \times 10^{15} \mathrm{~cm}^{-2} \cdot \mathrm{s}^{-1}$. 


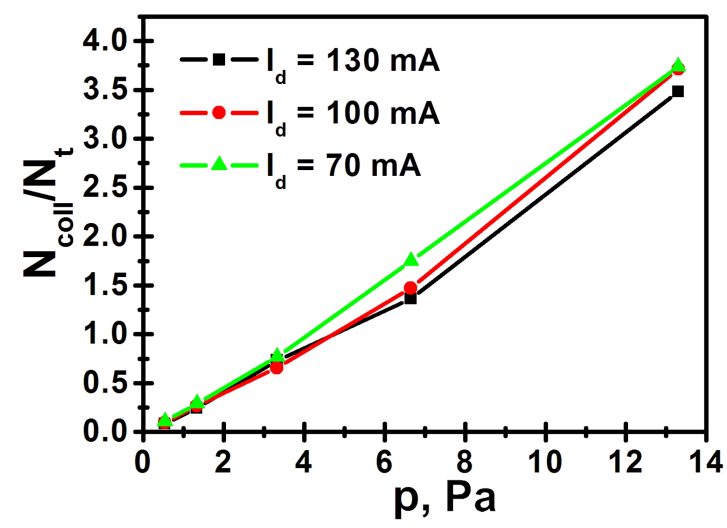

(a)

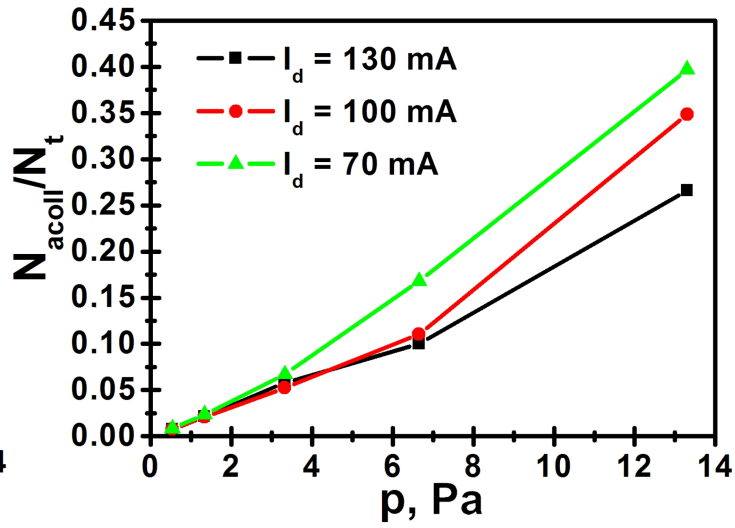

(b)

Fig. 6. (a) Ratio of collisions committed by atoms $\mathrm{N}_{\text {coll }} / \mathrm{N}_{c}$, (b) ratio of the number of atoms that have undergone collisions $\mathrm{N}_{\text {acoll }} / \mathrm{N}_{c}$ (where $\mathrm{N}_{c}$ - the number of atoms that have been sputtered from the target) at different currents and pressures.

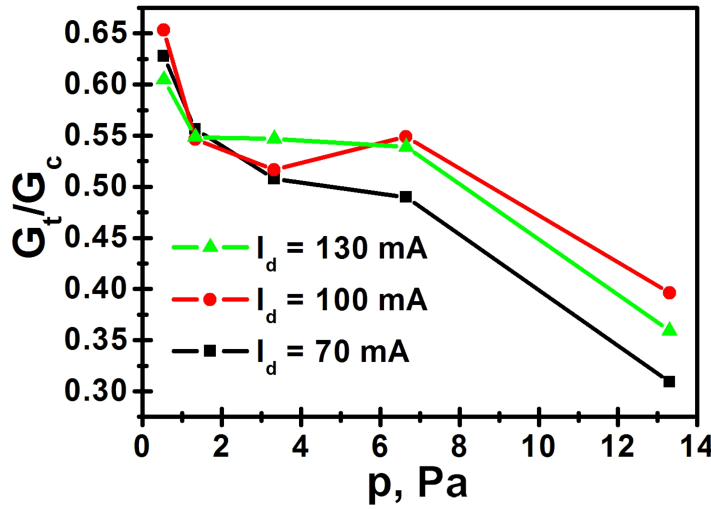

(a)

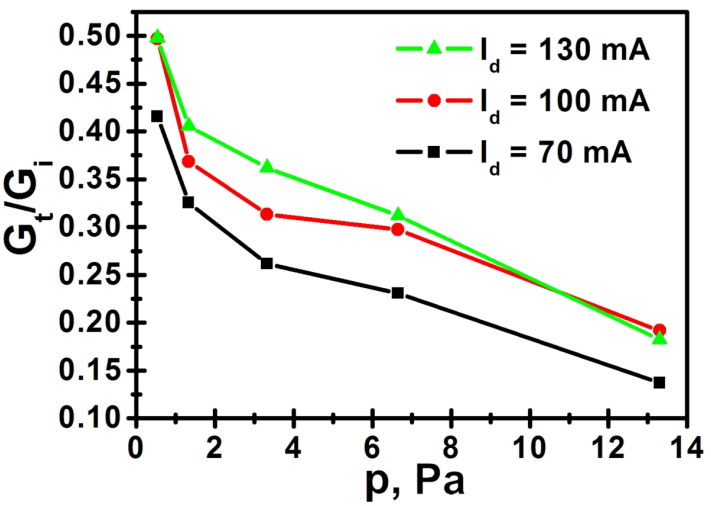

(b)

Fig. 7. (a) Ratio of the number of atoms on the substrate to the number of atoms sputtered from the target, (b) the relative number of atoms on the substrate compared to the number of ions bombarding the target.

This value is of the same order as the values obtained in our simulations. But it is necessary to consider that the area of the cathode-target is two times less in our work than in $[8,9]$, which, at the same discharge currents, provides larger density of the ion current on the cathode-target and the corresponding flow of the sputtered particles. Perhaps the discrepancy is also associated with unaccounted factors of the formation of the film in our computer model, which will be tested in our future studies.

\section{Conclusions}

A program based on Monte Carlo algorithm was developed for computer simulation of discharge in MSD with two zones of erosion. In the code, the main regularities of the target sputtering and the transfer of the sputtered material to the substrate were considered. The simulation was performed to estimate the flux density and the energy of sputtered atoms on the substrate at several discharge currents (70 mA, $100 \mathrm{~mA}, 130 \mathrm{~mA})$ and pressures of the working argon gas $(0.532 \mathrm{~Pa}$, 1.33 Pa, 3.32 Pa, 6.65 Pa, 13.3 Pa). (Those experimental values were measured on a graphite target, which could be used for synthesis of carbon nanomaterials and films.) The discharge simulation results (Fig. 2a) demonstrate good compliance with the behavior of a real discharge, such as the dependence of the discharge zones intensity on the working gas pressure (Fig. 1c, 1d). At a pressure of 


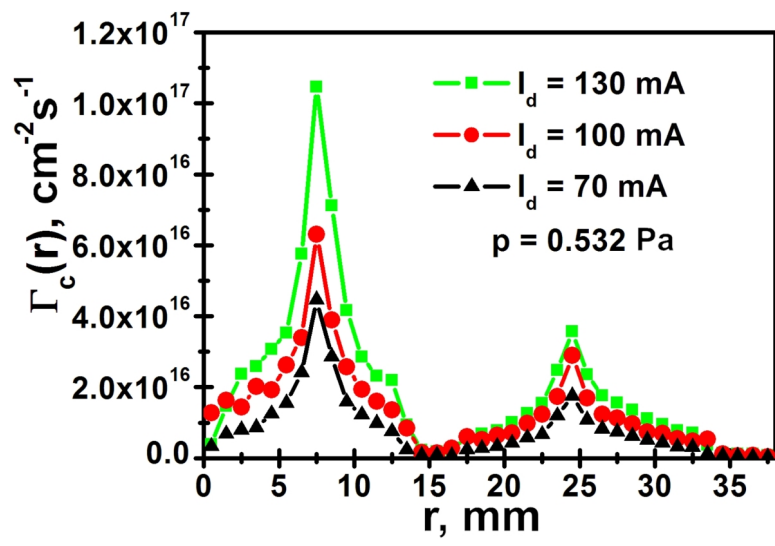

(a)

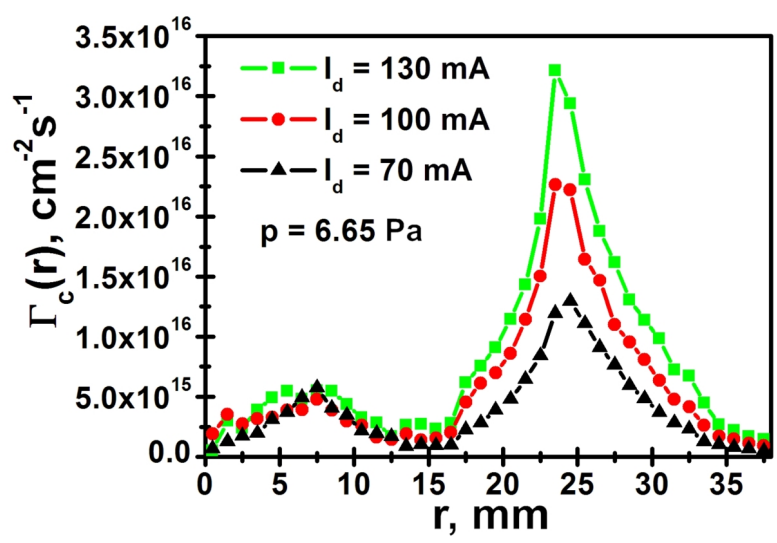

(c)

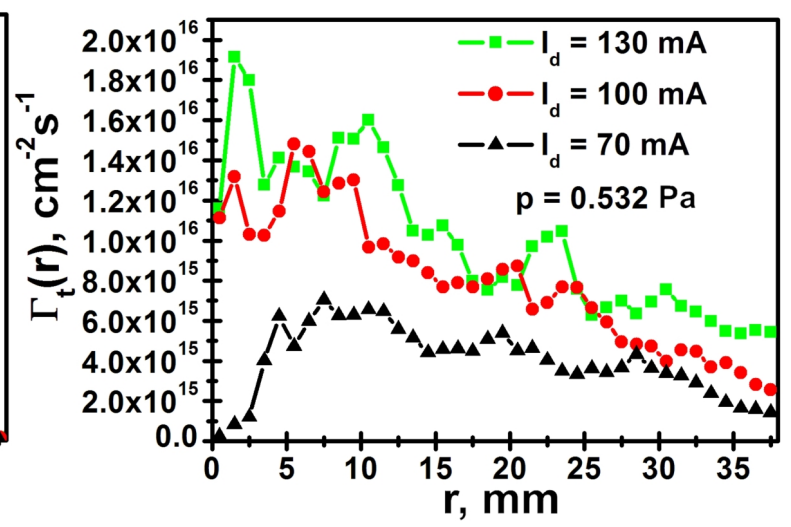

(b)

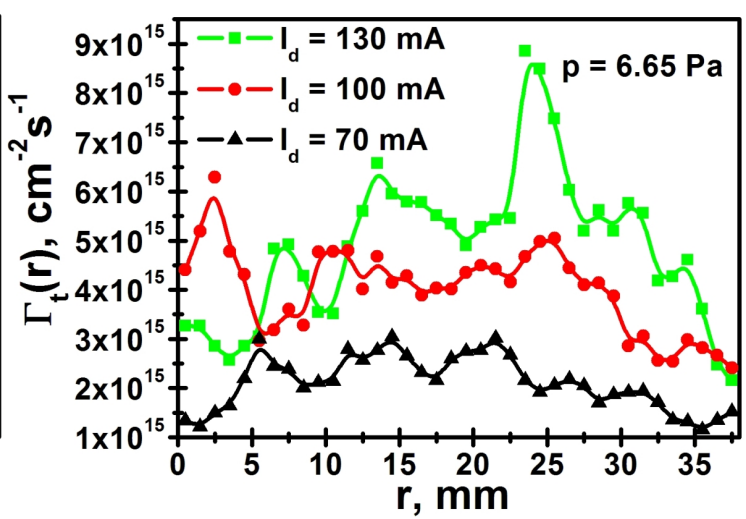

(d)

Fig. 8. The fluxes of carbon atoms at $p=0.532 \mathrm{~Pa}$ : (a) on the target, (b) on the substrate and at $\mathrm{p}=6.65 \mathrm{~Pa}$ : (c) on the target (d) on the substrate.

$0.532 \mathrm{~Pa}$ and current near $100 \mathrm{~mA}$ the inner zone is much more intensive than the outer one, but, for example, at $\mathrm{p}=6.65 \mathrm{~Pa}$ the relation is reversed.

It was demonstrated that the carbon flux from the target decreases when the discharge current decreases and also when the working gas pressure increases, which is associated with lower energy of the argon ions bombarding the target. In turn, the substrate current is much less (approximately of one order of magnitude) due to the loss of the particles. The simulations showed that many carbon atoms passing through the gas-filled gap from the target to substrate with the width of $40 \mathrm{~mm}$, do not attain the substrate because of their collisions with atoms of the working gas. If the pressure grows from $0.532 \mathrm{~Pa}$ to $13.3 \mathrm{~Pa}$ at all of the considered currents, the relative quantity of atoms, which have undergone the number of collisions (Fig. 6b) as the atomic flow losses (Fig. 7a), increases by $34 \%$ and $33.33 \%$, respectively.

The radial distributions of flux density of carbon atoms (Fig. 8b, 8d) and energy (Fig. 9) on the substrate distanced from the target at $40 \mathrm{~mm}$ are more uniform than the distributions of flux density (Fig. 8a, 8c) and energy (Fig. 9) on the surface of the cathode-target. It confirms the possibility of obtaining of qualitative and homogeneous films on this MSD. However, it has also been shown that changes in the discharge current density distribution between the zones (upon current and pressure variations) influenced, in a high degree, the distribution pattern of the flux density of carbon atoms at the center and the edge of the substrate.

The average energy of carbon atoms that reached the substrate did not differ a lot from their energy at the output of the target (Fig. 5b) due 


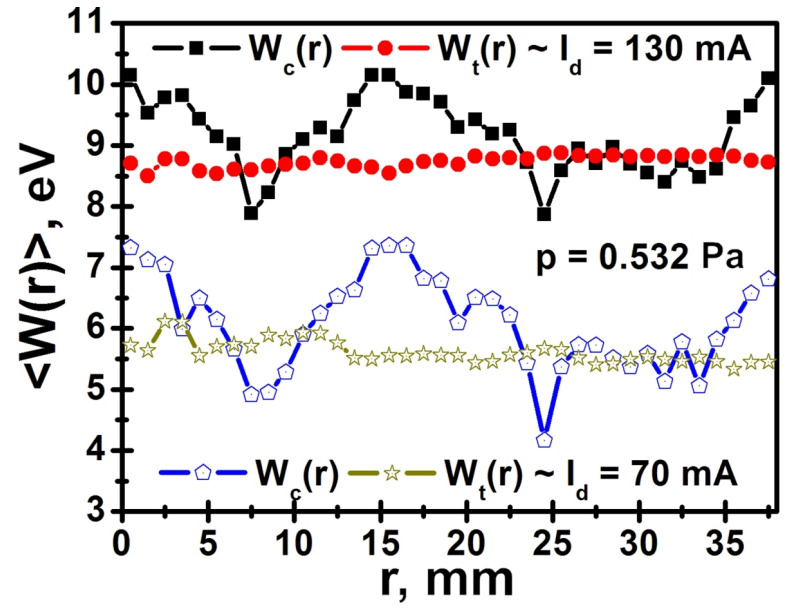

Fig. 9. The comparison of average energy distributions of carbon atoms along the radius of MSD at two discharge currents: $\mathrm{W}_{c}(\mathrm{r})-$ for atoms emerging from the target; $\mathrm{W}_{t}(\mathrm{r})$ - for atoms that have reached the substrate.

to the small number of collisions experienced by these atoms. The carbon particles energy exceeded $7.04 \mathrm{eV}$ only at pressures of $0.532 \mathrm{~Pa}$ (discharge currents $100 \mathrm{~mA}$ and $130 \mathrm{~mA}$ ) and $1.33 \mathrm{~Pa}$ (discharge current $130 \mathrm{~mA}$ ), which means that these modes could be suitable for deposition of carbon films, like in $[8,9]$.

Comparison of the results of the computer simulation with the obtained experimental results of synthesis of carbon films using the magnetron sputtering device (MSD) $[8,9]$ confirms the values obtained for the flux density of sputtered atoms on the substrate and also allows us to suggest that our MSD with two zones of erosion may be used for synthesis of carbon films, which contain carbon nanotubes and other nanoparticles.

\section{References}

[1] Bogdanov R.V., Kostiukevich O.M., Visnik Kiyivskoho nacionalnogo universitetu imeni Tarasa Shevchenka. Seriya: Fizyko-matematichni nauky, 1 (2012), 249 (in Ukrainian).

[2] Bogdanov R.V., Kostiukevich O.M., Problems of Atomic Science and Technology. Series: Plasma Physics (19), 1 (2013), 189.
[3] Bogdanov R., Kostiukevich O., Visnik Kiyivskoho nacionalnogo universitetu imeni Tarasa Shevchenka.: Radiofizyka ta electronika, 20 (2) (2013), 7.

[4] DANILIN B.S. Primeneniye nizkotemperaturnoy plazmy dlya naneseniya tonkih plenok, M., Energoatomizdat, 1989 (in Russian).

[5] KuZMicheV A.I. Magnetronnyie raspilitenye systemy. Kniga 1. Vvedenie v fiziku i tehniku magnetronnogo raspilenija, Avers, Kiev, 2008 (in Russian).

[6] Depla D., Mahieu S. And GReEne J.E., Sputter Deposition Processes, Processing in: MARTIN P.M. Handbook of Deposition Technologies for Films and Coatings, Third Edition: Science, Applications and Technology, William Andrew, 2010, p. 253.

[7] Kashtanov P.V., Smirnov B.M., Hippler R., Uspekhi Fizicheskikh Nauk, 177 (5) (2007), 473 (in Russian).

[8] Antonenko S.V., Mal'Cev S.N., Pribory i tekhnika eksperimenta, 3 (2005), 150 (in Russian).

[9] Antonenko S.V., Magnetronnaja tehnologija sozdanija grafitovyh pokrytij, nanotrubok, $i$ nanostruktur na ih osnove, in: Funkcional'nye materialy $i$ vysokochistye veshhestva,http://www.edu-cons . net/atlas_last/doc/444/Antonenko_rus.pdf, 2007, (in Russian).

[10] ShChUR D.V., Matysina Z.A., ZaginayChenko S.YU., Uglerodnyye nanomaterialy $i$ fazovyye prevrashcheniya $v$ nikh.: Monografiya, Nauka i obrazovaniye, Dnepropetrovsk, 2007 (in Russian).

[11] Graves D.B., Brault P., J. Phys. D Appl. Phys., 42 (2009), 194011.

[12] Bultinck E., Bogaerts A., J. Phys. D Appl. Phys., 41 (2008), 202007.

[13] Musschoot J., Depla D., Haemers J., De Gryse R., Plasma Sources Sci. T., 39 (2006), 3989.

[14] Musschoot J., Depla D., Haemers J., DE Gryse R., Plasma Sources Sci. T., 41 (2008), 1.

[15] QingQuan Q., QIngfu L., JingJing S., JiaO Y., Finley J., Plasma Sci. Technol., 10 (6) (2008), 694.

[16] Kucherenko E.T., Plasmotehnologia-97: Sb. nauch. trudov, RIP Vidavets, Zaporozhye, 1997, p. 121 (in Russian).

[17] Musil J., VlceK J., Baroch P., Magnetron Discharges for Thin Films Plasma, Processing in PAULEAU Y. (Ed.), Materials surface processing by directed energy techniques, Elsevier, 1990, p. 100.

[18] VOL'PYAS V.A., GOL'MAN YE.K., Zhurnal tekhnicheskoy fiziki, 70 (3) (2000), 13 (in Russian).

[19] Razvitiye product union. Tekhnicheskiy spravochnik. at http://razvitie-pu.ru/?page_id=949, 2013, (in Russian).

Received 2014-05-21 Accepted 2014-09-20 